\title{
SENSIBILIDADE DE SEMENTES DE ARROZ (Oryza sativa L.) SUBMETIDAS A POLUENTES QUÍMICOS ORIGINÁRIOS DA ATIVIDADE HUMANA ${ }^{1}$
}

DARIO MUNT DE MORAES ${ }^{2}$, CLAUDETE MIRANDA ABREU ${ }^{3}$, PAULO TRAJANO BURCK SANTOS MELO³, ADRIANE ALVES LIMA ${ }^{3}$, ROSIMERI ROCHA RODRIGUES ${ }^{3}$, GISELI LOUREIRO DUARTE ${ }^{3}$

\begin{abstract}
RESUMO - A contaminação de áreas com poluentes químicos pode ocasionar estresse na maioria das plantas. Assim, a finalidade desta pesquisa foi analisar e descrever o efeito de poluentes na germinação e no vigor de sementes de arroz. Foi utilizada uma amostra de sementes de arroz cv. BR-IRGA 410, safra 2000/2001. As sementes foram embebidas por uma hora nos seguintes poluentes químicos: fenol $\left(\mathrm{C}_{6} \mathrm{H}_{6} \mathrm{O}\right)$, ácido bórico $\left(\mathrm{H}_{3} \mathrm{BO}_{3}\right)$, cloreto de amônio $\left(\mathrm{NH}_{4} \mathrm{Cl}\right)$ e potássio fosfato monobásico $\left(\mathrm{KH}_{2} \mathrm{PO}_{4}\right)$, nas concentrações de zero (controle); cinco; 10 e $15 \mathrm{mg} \mathrm{l}^{-1}$. Logo após a embebição as sementes foram submetidas ao teste de germinação; primeira contagem da germinação; índice de velocidade de emergência das plântulas; emergência das plântulas em casa de vegetação; condutividade elétrica; comprimento da parte aérea e das raízes das plântulas e massa da matéria fresca e seca da parte aérea e raízes das plântulas. Dentre os poluentes químicos, nas concentrações testadas, $\mathrm{o} \mathrm{NH}_{4} \mathrm{Cl}$ e o $\mathrm{KH}_{2} \mathrm{PO}_{4}$, foram os que mais afetaram a qualidade fisiológica das sementes de arroz, acarretando diminuição no vigor.
\end{abstract}

Termos para indexação: poluentes, vigor, arroz, semente.

\section{SENSIBILITY OF RICE SEED (Oryza sativa L.) SUBMITTED TO CHEMICAL POLLUTERS ORIGINARY FROM HUMAN ACTIVITY}

\begin{abstract}
The contamination of areas with chemical polluters may cause stress on the majority of plants. In such case, the purpose of this research was to evaluate and to describe the effect of the polluters on germination and vigor of the rice seeds submitted to chemical polluters from human activity. Rice seeds of cultivar BR IRGA 410, crop year 2000/2001 were used. The seeds were soaked up by one hour in the following chemical polluters: phenol $\left(\mathrm{C}_{6} \mathrm{H}_{6} \mathrm{O}\right)$, boric acid $\left(\mathrm{H}_{3} \mathrm{BO}_{3}\right)$, chlorate ammonium $\left(\mathrm{NH}_{4} \mathrm{Cl}\right)$ and potassium phosphate monobasic $\left(\mathrm{KH}_{2} \mathrm{PO}_{4}\right)$, on zero (control), 5,10 and $15 \mathrm{mg} \mathrm{l}^{-1}$ quantities. Thereupon the soaking, the seeds were evaluated through the germination test, the first count in the germination test, the emergency rate index of the seedlings, the emergency of the seedlings in greenhouse conditions, the electric conductivity, the length of shoot and roots of the seedlings and the dry weight of the root and shoot of the seedlings. Among the chemical polluters the $\mathrm{NH}_{4} \mathrm{Cl}$ and $\mathrm{KH}_{2} \mathrm{PO}_{4}$, were those which affected most the physiological quality of rice seeds causing decrease on the vigor.
\end{abstract}

Index terms: polluters, vigor, rice, seed.

\section{INTRODUÇÃO}

Os processos de industrialização impulsionam a economia dos países, mas trazem consigo o perigo da degradação ambiental. Estes problemas afetam não apenas organismos

\footnotetext{
${ }^{1}$ Aceito para publicação em 19.08.2002.

${ }^{2}$ Prof. Dr., Depto. de Botânica Universidade Federal de Pelotas, PelotasRS, Cx. Postal 354.

${ }^{3}$ Aluno de Pós-Graduação Universidade Federal de Pelotas - Bolsista CNPq.
}

isolados como também o ecossistema como um todo (Arndt et al., 1995).

A contaminação de áreas com poluentes pode ocasionar, estresse na maioria das plantas agriculturáveis. Esta contaminação pode ocorrer de maneira natural, com depósitos superficiais de minerais ou produzidos pelo homem com a extração ou mineralização, aplicações de fertilizantes na agricultura e contaminantes oriundos do petróleo. A degradação ambiental resulta das atividades humanas por séculos até o presente, mas somente a poucas décadas o homem começou 
a preocupar-se com o impacto sobre as próximas gerações (Pessarakli \& Szabolcs, 1999).

O estudo das características da colonização e estabelecimento da flora em áreas contaminadas com diferentes níveis de poluentes, mostra que para algumas espécies estes níveis não são completamente tóxicos (família de musgos e briófitas), porém em concentrações mais elevadas afeta o metabolismo das plantas.

Estudos sobre a evolução à tolerância de genótipos a poluentes, em plantas superiores, tem ganhado interesse na fisiologia, principalmente de gramíneas e plantas utilizadas como cobertura.

Sintomas visuais de danos em plantas não podem, contudo, ser atribuídos em todos os casos a efeitos de emissões. Para um diagnóstico diferencial, portanto, é muito importante o conhecimento de modificações visíveis causadas por condições locais desfavoráveis, por manifestações de deficiência nutricionais ou por influências abióticas (Arndt et al., 1995).

A produtividade das culturas depende de vários fatores que interagem no meio-ambiente. Os fatores biológicos sofrem grandes influências dos compostos químicos lançados no ambiente na forma de resíduos da atividade industrial (Loomis \& Connor, 1996). As plantas como organismos sedentários e sensíveis a determinadas substâncias podem ser utilizadas como bioindicadores, no estudo do impacto da poluição ambiental (Larcher, 2000). Outros fatores, tais como estádio de desenvolvimento da planta, tempo de exposição ao metal e as diferentes espécies químicas dos elementos, podem também interferir nesses aspectos, refletindo nos teores dos metais nas diferentes partes da planta (Alloway, 1993). Até o momento poucos estudos foram realizados no sentido de se conhecer o papel da toxidade de poluentes na qualidade das sementes. Assim, a finalidade desta pesquisa foi analisar e descrever o efeito de poluentes na germinação e no vigor de sementes de arroz.

\section{MATERIAL E MÉTODOS}

O estudo foi conduzido no laboratório de Fisiologia de Sementes do Departamento de Botânica da Universidade Federal de Pelotas. Foi utilizada uma amostra de sementes de arroz cv. BR-IRGA 410, safra 2000/2001. As sementes foram embebidas por uma hora nos seguintes poluentes: fenol $\left(\mathrm{C}_{6} \mathrm{H}_{6} \mathrm{O}\right)$, ácido bórico $\left(\mathrm{H}_{3} \mathrm{BO}_{3}\right)$, cloreto de amônio $\left(\mathrm{NH}_{4} \mathrm{Cl}\right)$, potássio fosfato monobásico $\left(\mathrm{KH}_{2} \mathrm{PO}_{4}\right)$, nas concentrações de zero; 5; 10 e $15 \mathrm{mg} \mathrm{l}^{-1}$. Após a embebição as sementes foram submetidas ao teste de germinação - conduzido com 400 sementes (oito sub-amostras de 50 sementes) utilizando-se como substrato o rolo de papel germitest, previamente umedecido com água destilada (na proporção de 2,5 vezes o seu peso inicial), conforme Brasil (1992). A temperatura do germinador foi de $25^{\circ} \mathrm{C}$, com contagens no sétimo e 14 dias após a instalação do teste e os resultados foram expressos em porcentagem de germinação; primeira contagem da germinação - conduzido juntamente com o teste de germinação, sendo realizada apenas uma avaliação no sétimo dia após a semeadura e os resultados foram expressos em porcentagem de plântulas normais; índice velocidade de emergência das plântulas - determinado em casa de vegetação conforme Popinigis (1985), utilizando-se como substrato areia colocada em bandejas de poliestireno expandido com 200 células e a semeadura feita manualmente a profundidade de três centímetros. Foram utilizadas 200 sementes para cada tratamento em quatro sub-amostras de 50 sementes instaladas em linha. Observações diárias foram realizadas a partir do dia em que a primeira plântula emergiu, contando-se diariamente o número de plântulas em cada linha, até que este número permanece-se constante e o resultado foi dado pela média dos índices das repetições; emergência das plântulas em casa de vegetação - foi instalado de forma idêntica ao teste de velocidade de emergência em casa de vegetação, com apenas uma contagem aos 21 dias após a data da semeadura, sendo utilizadas quatro sub-amostras de 50 sementes por tratamento e os resultados expressos em porcentagem de emergência das plântulas; condutividade elétrica - foi determinada com três e 24 horas de incubação, utilizando-se quatro sub-amostras de 25 sementes para cada tratamento, as quais foram colocadas em copo de béquer com $80 \mathrm{ml}$ de água deionizada e mantidas em germinador com temperatura constante de $25^{\circ} \mathrm{C}$. A leitura da condutividade elétrica foi realizada em condutivímetro de bancada CA 150, conforme metodologia descrita por Krzyzanowski et al., (1991) e os resultados foram expressos em $\mu \mathrm{Sm}^{-1} \mathrm{~g}^{-1}$; comprimento da parte aérea $\mathbf{e}$ das raízes das plântulas - obtido aos 21 dias após a semeadura das plântulas (Popinigis, 1985) e os resultados expressos em milimetros; massa da matéria seca das plântulas obtidas aos 21 dias após a semeadura das plântulas (Popinigis, 1985). As plântulas foram colocadas em estufa a $75 \pm 1{ }^{\circ} \mathrm{C}$ até peso constante, determinando-se a matéria seca e os resultados expressos em mg planta ${ }^{-1}$. O delineamento estatístico utilizado foi o inteiramente casualizado, com quatro repetições. Os dados foram analisados estatisticamente e as médias foram comparadas pelo teste de Duncan, a $5 \%$. 


\section{RESULTADOS E DISCUSSÃO}

Analisando-se a Tabela 1, verifica-se que, de modo geral, os poluentes químicos nas concentrações testadas, não influenciaram significativamente a porcentagem média da germinação, que foi de $99 \%$, e nem a primeira contagem da germinação das sementes de arroz que foi de $50 \%$. O índice de velocidade de emergência (IVE) das plântulas em casa de vegetação (Tabela 1), obtido com sementes tratadas com $\mathrm{NH}_{4} \mathrm{Cl}$, alcançaram valores superiores ao controle. No entanto, pode-se observar que para os demais compostos as médias apresentaram-se significativamente semelhantes ao controle. O comprimento da parte aérea das plântulas (Tabela 2), quando comparados com o tratamento controle, foram afetados negativamente pela presença do $\mathrm{KH}_{2} \mathrm{PO}_{4}, \mathrm{H}_{3} \mathrm{BO}_{3} \mathrm{e} \mathrm{NH}_{4} \mathrm{Cl}$, sendo que, nas raízes o $\mathrm{KH}_{2} \mathrm{PO}_{4}$ estimulou o crescimento. Isto, sugere que o crescimento da parte aérea das plântulas é mais sensível a ação dos poluentes químicos do que o sistema radicular.

Dos compostos analisados, $\mathrm{o}_{4} \mathrm{Cl}$, foi o que induziu maior acúmulo de matéria seca da parte aérea das plântulas (Tabela 3). Este efeito, que favoreceu o aumento da matéria seca pode ser atribuído à presença de nitrogênio neste composto, estando este envolvido na síntese dos aminoácidos, vitaminas e pigmentos (Castro, 1987). Plântulas oriundas de sementes tratadas com fenol apresentaram reduzida matéria seca quando comparadas com o controle. Isto, pode ser devido ao fato que a presença de fenol causa redução no nível de ácido ascórbico nas folhas, lavando a estimulação da respiração, baixa produção de matéria seca, mudanças na permeabilidade e distúrbios no balanço hídrico (Larcher, 1986).

Na Tabela 3 pode-se observar que a massa da matéria seca da parte aérea das plântulas na presença de $\mathrm{KH}_{2} \mathrm{PO}_{4}$, foi reduzida na concentração de $10 \mathrm{mg} \mathrm{l}^{-1}$. A toxidez por potássio fosfato monobásico $\left(\mathrm{KH}_{2} \mathrm{PO}_{4}\right)$ segundo Nobel et al., (1983), em Potamogeton alpinus apresenta como limite para injúrias concentrações de $0,2 \mathrm{mg} \mathrm{l}^{-1}$ e letalidade de $50 \%$ em concentrações de $2 \mathrm{mg} \mathrm{l}^{-1}$. Em Elodea canadensis os limites para injúrias são concentrações de $0,5 \mathrm{mg} \mathrm{l}^{-1}$ e letalidade de $50 \%$ em concentrações maiores que $5 \mathrm{mg} \mathrm{l}^{-1}$. No entanto, os poluentes químicos não afetaram a massa da matéria seca das raízes (Tabela 3).

Os poluentes químicos, exceto $\mathrm{o} \mathrm{NH}_{4} \mathrm{Cl}$, não influenciaram a saída de solutos através das membranas celulares (Tabela 4). A conduti-vidade elétrica do lixiviado das sementes aumentou em função da concentração do $\mathrm{NH}_{4} \mathrm{Cl}$, tanto na determinação de três quanto na de 24 horas, em relação ao controle e demais poluentes químicos. $\mathrm{O} \mathrm{NH}_{4} \mathrm{Cl}$, provavelmente afeta negativamente a velocidade de rearran-jamento das membranas celulares, permitindo a lixiviação de sais minerais, açúcares, proteínas e outros componentes da semente e como conseqüência acelerando os processos de deterioração.

TABELA 1. Primeira contagem, germinação e índice de velocidade emergência de sementes de arroz cv. BR-IRGA 410, submetidas a poluentes químicos.

\begin{tabular}{lcccc}
\hline Poluente & $\begin{array}{c}\text { Concentração } \\
\left(\mathbf{m g ~ l}^{\mathbf{1}}\right)\end{array}$ & $\begin{array}{c}\text { Primeira contagem } \\
(\%)\end{array}$ & $\begin{array}{c}\text { Germinação } \\
(\boldsymbol{\%})\end{array}$ & IVE \\
\hline Controle & 0 & 92 & 99 & $4,8 \mathrm{bc}$ \\
Fenol & 5 & 98 & 98 & $4,6 \quad \mathrm{c}$ \\
$\mathrm{KH}_{2} \mathrm{PO}_{4}$ & 10 & 91 & 98 & $5,3 \mathrm{ab}$ \\
$\mathrm{H}_{3} \mathrm{BO}_{3}$ & 10 & 97 & 98 & $5,1 \mathrm{ab}$ \\
$\mathrm{NH}_{4} \mathrm{Cl}$ & 15 & 92 & 99 & $5,5 \mathrm{a}$ \\
\hline $\mathrm{CV}(\%)$ & & 11,30 & 3,86 & 7,71 \\
\hline
\end{tabular}

Médias seguidas por mesma letra não diferem entre si ao nível de significância de 5\% pelo Teste de Duncan. 
TABELA 2. Comprimento médio de plântulas de arroz cv. BR-IRGA 410, obtidas a partir de sementes submetidas a poluentes químicos.

\begin{tabular}{lccc}
\hline \multirow{2}{*}{ Poluente } & \multicolumn{3}{c}{ Comprimento $(\mathbf{m m})$} \\
\cline { 2 - 4 } & Concentração $\left(\mathbf{m g ~ l}^{-1}\right)$ & Parte aérea & Raízes \\
\hline Controle & 0 & $119 \mathrm{a}$ & $47 \mathrm{~b}$ \\
Fenol & 5 & $116 \mathrm{a}$ & $47 \mathrm{~b}$ \\
$\mathrm{KH}_{2} \mathrm{PO}_{4}$ & 10 & $109 \mathrm{~b}$ & $51 \mathrm{a}$ \\
$\mathrm{H}_{3} \mathrm{BO}$ & $110 \mathrm{~b}$ & $48 \mathrm{~b}$ \\
$\mathrm{NH}_{4} \mathrm{Cl}$ & 10 & $111 \mathrm{~b}$ & $48 \mathrm{~b}$ \\
\hline $\mathrm{CV}(\%)$ & 15 & 4,88 & 3,54 \\
\hline
\end{tabular}

Médias seguidas por mesma letra não diferem entre si ao nível de significância de 5\% pelo Teste de Duncan.

TABELA 3. Massa da matéria seca de plântulas de arroz cv. BR-IRGA 410, obtidas a partir de sementes submetidas a poluentes químicos.

\begin{tabular}{lccc}
\hline \multirow{2}{*}{ Poluente } & \multirow{2}{*}{ Concentração $\left(\mathbf{m g ~ l}^{\mathbf{1}}\right)$} & \multicolumn{2}{c}{ Matéria seca $\left(\mathbf{m g ~ p l a n t a}^{\mathbf{- 1}}\right)$} \\
\cline { 3 - 4 } & & Parte aérea & Raízes $^{2}$ \\
\hline Controle & 0 & $8,5 \mathrm{ab}$ & 5,8 \\
$\mathrm{Fenol}$ & 5 & $7,5 \mathrm{bc}$ & 7,0 \\
$\mathrm{KH}_{2} \mathrm{PO}_{4}$ & 10 & $6,8 \mathrm{c}$ & 7,5 \\
$\mathrm{H}_{3} \mathrm{BO}$ & $8,3 \mathrm{~b}$ & 6,8 \\
$\mathrm{NH}_{4} \mathrm{Cl}$ & 10 & $9,8 \mathrm{a}$ & 7,5 \\
\hline $\mathrm{CV}(\%)$ & 15 & 11,09 & 25,79 \\
\hline
\end{tabular}

Médias seguidas por mesma letra não diferem entre si ao nível de significância de 5\% pelo Teste de Duncan.

TABELA 4. Condutividade elétrica de sementes de arroz cv. BR-IRGA 410, submetidas a poluentes químicos. Tempo de incubação (três e 24horas).

\begin{tabular}{lccc}
\hline \multirow{2}{*}{ Poluente } & \multirow{2}{*}{ Concentração $\left(\mathbf{m g ~ l}^{-\mathbf{1}}\right)$} & \multicolumn{3}{c}{ Condutividade elétrica $\left(\boldsymbol{\mu} \mathbf{S ~ m}^{\mathbf{- 1}} \mathbf{g}^{\mathbf{- 1}}\right)$} \\
\cline { 3 - 4 } & & 3 horas & $\mathbf{2 4}$ horas \\
\hline Controle & 0 & $221 \mathrm{~b}$ & $998 \mathrm{bc}$ \\
Fenol & 5 & $221 \mathrm{~b}$ & $1073 \mathrm{bc}$ \\
$\mathrm{KH}_{2} \mathrm{PO}_{4}$ & 10 & $478 \mathrm{~b}$ & $1356 \mathrm{~b}$ \\
$\mathrm{H}_{3} \mathrm{BO}_{3}$ & 10 & $199 \mathrm{~b}$ & $924 \quad \mathrm{c}$ \\
$\mathrm{NH}_{4} \mathrm{Cl}$ & 15 & $2900 \mathrm{a}$ & $4078 \mathrm{a}$ \\
\hline $\mathrm{CV}(\%)$ & & 29,29 & 14,42 \\
\hline
\end{tabular}

Médias seguidas por mesma letra não diferem entre si ao nível de significância de 5\% pelo 


\section{CONCLUSÕES}

Q A germinação e a primeira contagem da germinação das sementes não foram afetadas pelos poluentes químicos nas concentrações utilizadas;

$\mathrm{Q}$ o $\mathrm{NH}_{4} \mathrm{Cl}$, aumenta o índice de velocidade de emergência das plântulas, porém induz dano na integridade das membranas celulares facilitando a lixiviação de solutos;

$\square$ o crescimento da parte aérea das plântulas, de modo geral, foi afetado negativamente pela presença dos poluentes, no entanto, estes, não tiveram efeito no crescimento das raízes e na massa da matéria seca;

$\square$ todos os poluentes químicos testados são descritos como agressores ao meio ambiente. Portanto, sugere-se mais estudos com relação a concentrações e/ou tempo de exposição.

\section{REFERÊNCIAS}

ALLOWAY, B.J. Heavy metals in soils. New York: John Wiley, 1993. 339p.

ARNDT, U; FOLRES, F.; WEINSTEIN, L. Efeitos do flúor sobre as plantas: Diagnose de danos na vegetação do Brasil. Universidade Federal do Rio Grande do Sul, 1995. 155p.

BRASIL. Ministério da Agricultura e reforma Agrária. Regras para análise de sementes. Brasília: SNDA/DNDV/CLAV, 1992. 365 p.

CASTRO, P.R.C.; FERREIRA, S.O.; YAMADA, T. Ecofisiologia da produção agrícola. Piracicaba: Associação Brasileira para Pesquisa da Potassa e do Fosfato, Editado por CASTRO, P.R.C. 1987. 249p.

KRZYZANOWSKI, F.C.; FRANÇA-NETO, J.B.; HENNING, A.A. Relato dos testes de vigor disponíveis para grandes culturas. Informativo ABRATES, Londrina, v.1,n.2, p.15-50,1991.

LARCHER, W. Ecofisiologia vegetal. RiMa, São Paulo, 2000, 531p. LARCHER, W. Ecofisiologia vegetal. E.P.U., São Paulo, 1986, 319p.

LOOMIS, R.S.; CONNOR, D.J. Crop ecology: Productivity and management in agricultural systems. Cambridge University Press, 1996. $528 \mathrm{p}$.

PESSARAKLI, M.; SZABOLCS, I. Soil salinity and sodicity as particular plant/crop stress factors. p.01-15 In: Handbook of Plant and Crop Stress, Second Edition, Revised and Expanded. Edited by Mohammad Pessarakli, 1999.

POPINIGIS, F. Fisiologia da semente. 2.ed. Brasília: AGIPLAN, 1985. 289p. 